\title{
A DOMINAÇÃO MASCULINA EM QUESTÃO: EMANCIPAÇÃO DAS MULHERES E PENSAMENTO FEMINISTA
}

\author{
THE MALE DOMINATION IN QUESTION: WOMEN'S EMANCIPATION AND FEMINIST THINKING
}

\section{RESUMO}

Neste artigo, partindo das reflexões de autoras como Firestone, Beauvoir, Butler, Scott e Preciado, apresentamos algumas de suas principais contribuições para a discussão da dominação masculina. Pretendemos investigar como algumas teóricas feministas, a partir da segunda metade do século XX, problematizaram a dominação masculina e, ao mesmo tempo, construíram teorias para alcançar a emancipação feminina e a revolução feminista. Ao longo do estudo, observamos como as estruturas de poder assumem diversas formas de atuação na tentativa de normatizar os corpos e comportamentos das mulheres. Da mesma forma, as alternativas apresentadas pelas autoras, aqui destacadas, ressaltam a necessidade de uma diversidade de abordagens para o questionamento e a transformação dessas estruturas, uma vez que a própria crítica feminista não se configura como um campo coeso, tendo em vista as interseções com outras reflexões e conceitos (como os de classe e de raça).

Palavras-chave: Feminismo. Dominação masculina. Estudos de gênero. Corpo. Mulheres.

\begin{abstract}
In this paper, based on the reflections of authors such as Firestone, Beauvoir, Butler, Scott and Preciado, we present some of their main contributions to the discussion of male domination. We intend to investigate how some feminist theorists, from the second half of the twentieth century, have problematized male domination and, at the same time, constructed theories to achieve female emancipation and feminist revolution. Likewise, the alternatives presented by the authors highlighted stress the need for a diversity of approaches to question and transform these structures (since feminist criticism itself is not a cohesive field) taking into account the intersections of other reflections and concepts (such as class and race).
\end{abstract}

Keywords: Feminism. Male domination. Gender studies. Body. Women.

Marcus V. Reis

Professor da Faculdade de História da Universidade Federal do Sul e Sudeste do Pará (UNIFESSPA).

Camila M. Cargnelutti

UFSM. Email: camila.m.cargnelutti@gmail.com 


\section{Introdução: a tomada de consciência sobre a dominação masculina}

A partir de $A$ dialética do sexo, obra publicada originalmente em 1970, Shulamith Firestone consagrou-se como uma das primeiras teóricas do movimento feminista radical, por ter lançado novas perspectivas referentes ao processo de dominação dos homens sobre as mulheres, assim como alternativas possíveis para a subversão desse processo, ou seja, para o que Firestone compreendeu como a revolução feminista. Entre as teóricas marxistas, por sua vez, a temática da "revolução sexual" foi, segundo Joan Scott (1995: 9), um dos principais pilares para o desenvolvimento de uma série de estudos interessados na análise da sexualidade como forma de problematizar a "política sexual" vigente no mundo contemporâneo. Autora de Calibã e a Bruxa, a historiadora Silvia Federici (2017: 11) caracterizou as três décadas de trabalho e pesquisa que resultaram na publicação da sua obra como uma "contribuição para o movimento de libertação das mulheres e, em particular, para o combate à subordinação das mulheres aos homens". Essa afirmação não surpreende, uma vez que a própria autora pertenceu ao movimento feminista localizado na mesma década de publicação do trabalho de Shulamith. Em 1972, Federici filiouse ao Wages for Housework Campaign (Campanha por um salário para o trabalho doméstico), protagonizando intensos debates a favor da libertação das mulheres.

A política feminista é o ponto de partida para a análise da História das Mulheres, afirma Scott (1992: 64), embora não devamos interpretá-la como condição definidora de todo o histórico referente a esse campo de conhecimento. Ainda assim, esse vínculo com o movimento feminista das décadas de 1960-1970 serve de exemplo para demonstrar como a temática da revolução feminista - segundo o que defendeu Firestone - ou da libertação das mulheres - conforme apontou Silvia Federici - também abalou os meios acadêmicos, amplamente masculinos, a partir desse período.

Retomando Firestone (1976), para que a revolução destacada pela autora se materialize, são necessárias algumas condições como, por exemplo, a existência de um determinado nível de evolução social e uma certa sofisticação tecnológica, imprescindível para que os papéis pré-determinados biologicamente para homens e mulheres, tais como a reprodução, possam ser superados. Para tanto, Firestone sublinha a necessidade de empreender uma tarefa que não é particularmente simples: promover uma (res-)sensibilização a respeito do sexismo, questionando não somente a cultura ocidental em uma percepção mais ampla, como também a própria organização da cultura e, mais ainda, a própria organização da natureza. O que a autora propõe pode ser compreendido como uma tomada de consciência acerca dos processos de exclusão e opressão sobre as mulheres e de dominação dos homens, para que, a partir dessa conscientização, seja possível agir e mudar essa situação: "sua dolorosa sensibilidade em relação à opressão da mulher existe com um único propósito: eliminá-la finalmente” (Firestone, 1976: 12). 
A compreensão do surgimento e da evolução desse processo de opressão e dominação, assim como das instituições através das quais opera atualmente, é fundamental para a transformação almejada. Apesar de recorrer às teorias construídas por Marx e Engels, visto que ambos desenvolveram um método de análise simultaneamente dialético e materialista, a autora ressalta que a opressão das mulheres não pode ser explicada apenas sob uma interpretação estritamente econômica. Essa mesma crítica aparece, décadas depois, com o trabalho de Joan Scott. Ao discorrer sobre as teóricas marxistas, a autora percebeu que, embora interessadas em uma abordagem histórica, grande parte dessas autoras permaneceu na "causalidade econômica", interpretando o patriarcado como um movimento em constante mudança, desde que atrelado às relações de produção (Scott, 1995: 78). Essa mesma ressalva pode ser encontrada na já mencionada obra de Silvia Federici, principalmente quando a autora tece algumas críticas acerca do conceito de "acumulação primitiva", defendido por Marx. Sem nos aprofundarmos nas teorizações acerca desse conceito - até porque a própria autora não se propôs a isso salientamos que o interesse de Federici foi o de problematizar a ideia de acumulação primitiva a partir da abordagem feminista. Concluiu, assim, que as abordagens de Marx negligenciaram a dimensão sexual no processo de emergência do capitalismo:

Devo acrescentar que Marx nunca poderia ter suposto que o capitalismo preparava o caminho para a libertação humana se tivesse olhado sua história do ponto de vista das mulheres. Essa história ensina que, mesmo quando os homens alcançaram certo grau de liberdade formal, as mulheres sempre foram tratadas como seres socialmente inferiores, exploradas de modo similar às formas de escravidão (Federici, 2017: 27).

A proposta de Firestone, para não reproduzir esta simples causalidade econômica nas interpretações referentes à dominação masculina, consiste em compreender a história e o mundo como um processo, com elementos opostos inseparáveis e inter-relacionados dinamicamente, conjugando essa compreensão com uma visão materialista, tentando mapear traços reais para o desenvolvimento das classes econômicas e para as mudanças históricas e culturais. Nesse sentido, conforme salienta a autora, a análise de classes, proposta pelos teóricos marxistas, não se aprofunda o suficiente no substrato sexual da opressão - aspecto igualmente apontado, por exemplo, nas críticas de Federici. Diante dessa negligência, essas teorias são consideradas por Firestone como teorias que não permitem a inteira compreensão do processo de dominação masculina sobre as mulheres.

Na sequência de sua obra, ainda que teça elogios ao ineditismo do trabalho de Simone de Beauvoir, em O Segundo Sexo (publicado originalmente em 1949), principalmente por ter assentado (pela primeira vez) o feminismo em bases históricas e culturais, Firestone (1976) acredita que, talvez, Beauvoir tenha ido longe demais, ao postular que a dualidade (o homem como o Mesmo e a mulher como o Outro) não 
fosse, em primeira instância, de caráter sexual, mas fundada no fato de a mulher ser diferente do homem, ou seja, o de se configurar como a alteridade em relação a ele. A partir dessa concepção, Beauvoir documentou cuidadosamente circunstâncias biológicas e históricas que relegaram a mulher à categoria de Outro. Sobre essa questão, Firestone (1976: 17) afirmou que talvez seja necessário pensar justamente que existe uma "possibilidade muito mais simples e mais provável, ou seja, que o dualismo básico brotava do próprio sexo”. Duas décadas após as considerações de Firestone, a também filósofa Judith Butler (2016: 58-59) retomou a obra de Beauvoir afirmando que, embora a autora tenha subestimado o falocentrismo, cabe considerar que, "se há algo de certo na afirmação de Beauvoir [...] decorre que mulher é um termo em processo, um devir, um construir de que não se pode dizer com acerto que tenha uma origem ou um fim".

Considerando a argumentação de Firestone, sustentada pelo interesse da autora em consolidar a ausência de distinções sexuais, questionamo-nos se seria possível, na prática, a eliminação de toda e qualquer diferenciação sexual entre homens e mulheres para que a revolução sexual seja alcançada? E, caso seja viável, seria esse realmente o resultado almejado para uma sociedade "pós-revolução feminista”? Esses são alguns dos questionamentos que a leitura e a discussão da obra de Firestone, em diálogo com algumas teóricas feministas contemporâneas, como Preciado e Butler, instigam-nos a refletir e a desenvolver no presente estudo. Além da proposta alinhada com o movimento feminista radical norte-americano de Firestone, que outras possibilidades de liberação feminina/feminista são abordadas por diferentes autoras, em diferentes contextos?

O breve diálogo exposto acima, referente ao debate de Firestone com o trabalho de Simone de Beauvoir, indica que a temática da dominação masculina, bem como as discussões referentes a uma possível emancipação das mulheres frente a essa dominação, não estão circunscritas aos pressupostos de ambas as autoras. Se considerada a obra de Beauvoir como marco temporal acerca dessas discussões, ou seja, o ano de 1949, pode-se afirmar que uma série de autoras se debruçou criticamente sobre essa temática e no objetivo de teorizar sobre as possíveis alternativas para a efetivação da emancipação das mulheres diante dos mais variados contextos patriarcais e misóginos. Desde a emergência da História das Mulheres aos estudos vinculados à teoria queer, pode-se igualmente afirmar que essas análises não seguiram a mesma linha interpretativa, ainda que interessadas em problematizar e refletir sobre o mesmo tema. Por essas razões, este trabalho pretende investigar como algumas teóricas feministas, a partir da segunda metade do século XX, localizaram e historicizaram a dominação masculina, problematizaram-na e construíram teorias voltadas ao objetivo de traçar possíveis caminhos para a emancipação feminina e para a revolução feminista. Cientes da multiplicidade de versões e interpretações que acompanha a própria crítica feminista, tendo em vista a cada vez maior interseção com outros conceitos e teorias (vide as reflexões sobre raça e classe), as análises seguintes buscarão dar conta de parte dessas reflexões. 


\section{Historicizando a dominação masculina}

Interessada em analisar a genealogia das categorias de sexo, gênero e desejo, considerando-as como categorias fundacionais das relações de poder que demarcam o binarismo homem/mulher, Judith Butler (2016: 10) buscou na "genealogia" - termo retirado dos pressupostos de Michel Foucault e Nietzsche - a sustentação para a sua recusa em investigar as origens do gênero ou, nas suas palavras, "a verdade íntima do desejo feminino, uma identidade sexual genuína ou autêntica”. Como uma das principais consequências decorrentes dessa escolha, a fundamentação de que o "feminino" não é uma categoria estável e a necessidade de descentralizar o falocentrismo e a heterossexualidade compulsória foram os principais caminhos tomados pela autora de Problemas de gênero. Diante dessas posições, Butler (2017: 22-23) defendeu que o questionamento da universalidade e unidade do "sujeito do feminismo", bem como da existência do patriarcado como uma noção universal, possibilitará a visualização das diversas intersecções culturais, sociais e políticas que contribuem para a construção do sujeito "mulheres". Além disso, o reconhecimento de um patriarcado distante desse caráter universal nos proporcionará investigar concretamente os mecanismos de opressão do gênero e, mais ainda, como esses mecanismos são diversificados conforme os contextos em que são construídos e reproduzidos (Butler, 2017: 37).

Consoante às argumentações defendidas por Butler, afirmamos que a dominação masculina não é restrita a um determinado contexto histórico, tampouco assume uma unidade normativa de controle e determinação dos gêneros. Em outras palavras, essa dominação pode ser visualizada nos mais diversos períodos e através das distintas atuações das estruturas de poder - até porque a organização dessas estruturas não seguiu um mesmo modelo ao longo dos diversos contextos. Este item pretende, assim, investigar como algumas teóricas feministas não apenas reconheceram a existência dessa dominação, mas, também, construíram uma série de pressupostos cujo objetivo residiu em problematizar essa noção, a fim de demonstrar como a opressão às mulheres é um fenômeno histórico marcado por uma multiplicidade de estratégias normativas protagonizadas por inúmeras instituições.

Em A dialética do sexo, Firestone desenvolveu uma análise em que a própria biologia se encontra na base do dualismo entre o homem e a mulher, concepção que fundamenta as bases do feminismo radical defendido pela autora. Nessa perspectiva, a família biológica, como "a unidade básica de reprodução homem/mulher/criança, em qualquer forma de organização social” (Firestone, 1976: 18), tem um papel essencial, na medida em que se caracteriza por alguns fatos que, embora não imutáveis, são fundamentais para a condição da mulher nesse contexto. Dentre esses fatos, Firestone destaca que: 1) as mulheres estão à mercê de sua biologia - menstruação, menopausa, partos, amamentação, cuidado com os filhos -, tornando-as dependentes dos homens (através da figura de pais, irmãos, maridos, clã, comunidade em geral) para a sobrevivência física durante significativos períodos de sua vida; 2) os filhos são 
dependentes dos adultos por mais tempo para sua sobrevivência e crescimento; 3) existe uma interdependência básica entre a mãe e o filho, o que acabou moldando a psicologia das mulheres e das crianças; 4) existem diferenças naturais de reprodução entre os sexos, o que levou à primeira divisão de trabalho baseada no sexo (estando nas origens também das posteriores divisões em classes econômicas e culturais).

Algumas das questões que envolvem a relação entre a opressão das mulheres e das crianças são aprofundadas no capítulo IV da sua obra (intitulado "Abaixo a infância”), no qual a autora propõe que o vínculo entre ambas se constitui como uma opressão compartilhada, uma vez que o núcleo da opressão feminina é representado pelo seu papel de reprodutora e educadora de crianças. Esse papel é reforçado pela conjugação familiar patriarcal - as mulheres foram, ao longo da história e em todos os tipos de cultura, oprimidas devido a suas funções biológicas, sendo a família patriarcal apenas a mais recente dentre essas variações e, desenvolvendo-se até sua versão atual, a família nuclear patriarcal. Do século XIV em diante, como também foi notada por Federici (2017), essa configuração familiar nuclear intensificou ainda mais a opressão feminina. Nesse sentido, Firestone (1976) reforça que, para o feminismo radical proposto em sua obra, os princípios da dominação masculina não estão primordialmente localizados na cultura e no contexto histórico, tal como preconizou Beauvoir anteriormente, mas no processo reprodutivo, sendo essencialmente baseados nas diferenças sexuais e biológicas entre o homem e a mulher.

Ao revisitar a temática da caça às bruxas, que marcou sensivelmente a história do Ocidente medieval e moderno europeu, Silvia Federici encontrou na relação das mulheres com a procriação um dos principais sustentáculos para o surgimento e longa duração desse fenômeno. Mais ainda, entendeu essa relação como a base fundamental para a análise acerca do desenvolvimento das relações capitalistas após a fragmentação do feudalismo, em que o disciplinamento e o aprisionamento dos corpos femininos se tornaram pautas centrais nesse novo contexto. Nota-se, portanto, que, diferentemente da abordagem de Firestone, a autora de Calibã e a Bruxa compreendeu o contexto histórico como aspecto essencial para analisar a relação entre mulheres e reprodução e como, ao longo da história, essa relação marcou o caráter da dominação masculina. Assim, Federici defendeu que a formação dos Estados Nacionais e a consolidação de uma economia capitalista foram essenciais para a transformação desses corpos femininos em "território político, controlados pelos homens e pelo Estado: a procriação foi colocada diretamente a serviço da acumulação capitalista" (Federici, 2017: 178).

A preocupação com as bases históricas referentes ao patriarcalismo pode ser visualizada em Eunucos pelo reino de Deus, obra publicada em 1988, sob a autoria da teóloga alemã Uta Ranke-Heinemann. E, diferentemente do recorte temporal utilizado por Firestone e Silvia Federici, a autora recorreu à Antiguidade Clássica como marco inicial da dominação masculina, pois, com o advento posterior do Cristianismo, alcançaria maior amplitude na tentativa de controlar os corpos e comportamentos das mulheres. Não é à toa que, segundo Ranke-Heinemann (1996: 24), a figura de Aristóteles foi levada à condição de "quase-padre na Igreja em questões 
relacionadas à mulher", mais precisamente com o reconhecimento da autoridade de Tomás de Aquino, grande responsável pelo resgate e apropriação dos pressupostos aristotélicos no contexto católico.

Ampliando as discussões sobre as questões biológicas no interior do feminismo radical, Firestone desenvolve, no Capítulo VI de A dialética do sexo, a temática do amor como uma dessas manifestações e como um dos principais pivôs da opressão das mulheres no mundo contemporâneo. Para Firestone (1976: 151), o amor se torna corrompido pelo "desequilíbrio desigual de poder", tendo consequências destrutivas para o lado feminino da sociedade, apenas por conta de seu contexto de desigualdade, o qual se manifesta, por exemplo, na idealização das mulheres, na dependência econômica, na necessidade de posse e controle masculino sobre as mulheres e na requerida aprovação de um homem para a validação da existência da mulher como sujeito. Nesse contexto, a cultura do romance, conforme abordado no Capítulo VII do seu livro, torna-se corrompida: "quando falamos de amor romântico, queremos dizer o amor corrompido por seu contexto de poder - o sistema de classes sexuais - numa forma de amor doentia, que, por sua vez, reforça esse sistema de classes sexuais" (Firestone, 1976: 169). Para a autora, o romantismo desenvolveu-se em proporção à libertação das mulheres de sua biologia, justamente como uma forma da supremacia masculina tolhê-las, novamente, em suas pequenas liberdades alcançadas com a evolução social lenta e gradativa. Surge daí a necessidade masculina de enrijecer instituições artificiais, tal como a família nuclear patriarcal, consolidada por meio do casamento pautado no pressuposto do amor romântico.

Outras manifestações negativas da divisão da sociedade em classes sexuais, baseadas em aspectos biológicos, são abordadas nos capítulos VIII e IX da obra de Firestone, os quais tratam, respectivamente, da cultura (masculina) e da dialética sexual da história da cultura. Nesses capítulos, a autora salienta como a cultura está "tão saturada de preconceitos masculinos, que as mulheres quase nunca têm uma chance de ver-se culturalmente, através dos próprios olhos” (Firestone, 1976: 182). Nesse sentido, em uma sociedade que parte da desigualdade entre os gêneros, não seria possível, conforme ressalta a autora, a produção de arte autêntica por parte das mulheres, pois, uma vez inseridas em um meio que as limita em suas expressões e manifestações artísticas, literárias e culturais, estão impedidas de alcançar imagens autênticas da sua realidade. Para que isso acontecesse de fato, Firestone (1976: 184) acredita que "seria necessário uma recusa de toda a tradição cultural para que as mulheres chegassem a produzir uma arte 'feminina' verdadeira”. Pois, na atual, as mulheres seriam (e são) julgadas e classificadas conforme padrões e valores estéticos e culturais masculinos - não haveria um lugar autêntico para a mulher nessa tradição cultural, literária e artística dominada pelos homens.

Sobre os processos de silenciamento e exclusão das mulheres na construção dos cânones e histórias literárias nacionais, desde a década de 1970, no âmbito da teoria e da crítica literária, alguns conceitos e valores - até então considerados como universais ou neutros - têm sido questionados e problematizados. Esses valores, determinantes para a formação dos cânones literários tradicionais, manifestam 
historicamente relações de poder e ideologias sociais, privilegiando determinadas vozes e obras e marginalizando ou excluindo outras. Conforme explica Rita Schmidt (2008: 50), esse processo de questionamento ao cânone cultural, literário e artístico, "se vale de argumentos que evidenciam o quanto os cânones sustentam um mesmo código escritural, cuja função é projetar uma representação idealizada da cultura, como se esta constituísse uma totalidade sem fraturas". Nesse sentido, ter consciência dos mecanismos, valores e subjetividades envolvidas na constituição dos cânones, assim como os privilégios e consequentes exclusões decorrentes desse processo, é fundamental para compreendermos como, em uma sociedade patriarcal, as mulheres artistas e escritoras foram historicamente excluídas também dos âmbitos culturais e dos sistemas canônicos artísticos e literários.

Além disso, não somente nas artes e nas letras as mulheres foram silenciadas historicamente - também no campo científico a dualidade sexual desse sistema teve manifestações negativas para elas. No entanto, o entendimento de que essas diferenças e, dentre elas, principalmente a reprodução biológica, configuramse como sustentáculos da dominação masculina sobre as mulheres, assim como aprisionamentos biológicos para elas, não significa, de forma alguma, considerar a revolução feminista como perdida por fatores tradicionalmente apontados como "naturais". Conforme explica Firestone (1976: 19), "admitir que o desequilíbrio sexual do poder está baseado biologicamente não significa perder nossa causa. Nós não somos animais há muito tempo. E o Reino da Natureza não reina absolutamente”. Dessa forma, não são mais possíveis, ou aceitáveis, tentativas de justificar a manutenção de um sistema discriminatório e opressivo com aproximadamente metade da população mundial, sob o pretexto de que essa assimetria de poder, que tende negativa e invariavelmente para o lado feminino, tem origens na natureza ou na biologia.

Para a autora, uma vez que a cultura e a ciência foram corrompidas pela polarização sexual, a alternativa que deve ser buscada seria, novamente, a revolução feminista e cultural $^{2}$, com o intuito de eliminar completamente as diferenças sexuais que estariam na origem das demais distorções sexuais, em termos culturais, científicos, artísticos e literários. Essa revolução cultural deveria propor a reintegração entre o masculino (modo tecnológico) e o feminino (modo estético) e "criar uma cultura andrógina, que vá além não só de cada uma dessas correntes culturais tomadas individualmente, como também da soma de sua integração. Mais do que

1 No Brasil, a pesquisadora Zahidé Muzart (1999) realizou um extenso trabalho de recuperação e resgate de escritoras do século XIX. Sua pesquisa foi organizada em antologia intitulada Escritoras brasileiras do século XIX, publicada pela Editora Mulheres em três volumes, nos anos de 1999, 2004 e 2009.

2 "E assim como a fusão das distintas classes sexuais, raciais e econômicas é uma precondição para a revolução respectivamente sexual, racial ou econômica, assim a fusão da cultura estética com a tecnológica é a precondição para uma revolução cultural. E assim como a meta revolucionária das revoluções sexual, racial e econômica é, em vez de um mero nivelamento dos desequilíbrios de classe, assim o resultado final de uma revolução cultural deve ser, não meramente a integração das duas correntes da cultura, mas a eliminação da própria cultura, como nós a conhecemos" (Firestone, 1976: 203). 
um casamento, é preciso a abolição das próprias categorias culturais, uma anulação mútua" (Firestone, 1976: 219).

Todo esse histórico de silenciamentos e tentativas endereçadas à normatização dos corpos e comportamentos das mulheres, protagonizadas por uma estrutura patriarcal e misógina, pode ser entendido, por exemplo, através da "retórica da violência”, conforme sustentou Teresa de Lauretis, em The violence of rethoric (1985). Para a autora, há uma relação entre a violência e a retórica, quando o discurso sobre as diferenças sexuais é colocado como aspecto determinante para as relações entre homens e mulheres. Isto porque, segundo Lauretis (1985), esse discurso, na maioria das vezes, está sustentado por uma visão eminentemente masculina, ou seja, as mulheres são interpretadas a partir da visão dos homens:

[...] pois a sexualidade, não só no discurso geral e tradicional, mas também no de Foucault, é construída não como gênero (como tendo uma forma masculina e uma forma feminina), mas simplesmente como masculina. Mesmo quando está localizada, como muitas vezes é, no corpo da mulher, a sexualidade é um atributo ou propriedade do homem (Lauretis, 1985: 37).

E a retórica acerca dessas interpretações está acompanhada de práticas de violência que, nem sempre, partem de uma única fonte, tampouco se restringem à violência física (Lauretis, 1985: 32-33). Sendo assim, mais do que compreender a formação dos Estados Nacionais, a partir do seu vínculo com a crescente normatização e submissão das mulheres aos homens, conforme sustentado por Federici (2017), interessa avaliar em que medida as práticas de violência são reproduzidas para além de uma única fonte normativa ou de uma instituição específica. A violência é, portanto, en-gendrada (en-gendered, isto é, "engendrada em termos de gênero") e deve ser analisada como uma categoria necessária para compreender como as identidades de gênero são construídas, reguladas ou subvertidas historicamente.

Também voltada ao campo teórico, Joan Scott problematizou em Gender: A Useful Category of Historical Analysis (1986) não apenas os usos que os pesquisadores, principalmente as teóricas feministas, faziam do conceito de "gênero", mas, principalmente, defendeu a sua utilização através de uma perspectiva histórica. Segundo os apontamentos de Scott (1986), seu artigo foi escrito em um contexto cuja utilização do gênero estava sustentada em duas principais interpretações que, a seu ver, não ultrapassavam os limites das Ciências Sociais da época. Explicações universais e perspectivas generalizantes predominavam nas análises dos historiadores, sem quaisquer questionamentos mais aprofundados a respeito dos sujeitos e das estruturas de poder. Assim, a única forma de fugir dessa perspectiva homogeneizante residiria em compreender que o gênero é um "elemento constitutivo de relações sociais baseadas nas diferenças percebidas entre os sexos”, além de ser uma "forma primária de dar significado às relações de poder" (Scott, 1995: 86). A partir dessa compreensão e de uma perspectiva histórica, é possível analisar como os 
símbolos culturais referentes às mulheres são construídos e, mais ainda, vinculados aos conceitos normativos cuja função primordial consiste em padronizar os papeis sociais relacionados a elas.

Judith Butler (2015: 4) chega a usar a expressão "discursos autorizados de gênero" para destacar o peso que as instâncias religiosas, médicas e jurídicas assumem na delimitação de quais funções sociais os homens e, principalmente, as mulheres devem seguir. Por isso, a autora entende que o gênero precede os indivíduos, pois é encarnado em padrões de masculinidade e feminilidade produzidos e reproduzidos ao longo da história, ao mesmo tempo em que atua sobre esses mesmos indivíduos, obrigando-os a reproduzi-lo. Em Problemas de Gênero, a autora analisou as relações entre sexo, gênero e desejo, entendendo que essas categorias estão inscritas no que a própria Butler definiu como "heterossexualidade compulsória" ou "matriz heterossexual"3. Ou seja, na medida em que o gênero se propõe como uma construção unitária, capaz de reafirmar o binômio masculino/feminino, ele contribui diretamente para a manutenção de toda uma condição normativa decorrente dessa relação. Tem-se, portanto, a construção e a manutenção de hierarquias que, independente do contexto histórico, objetivam reproduzir as noções de inferioridade e de submissão nas quais as mulheres são condicionadas para a manutenção de uma dada ordem social. Por sua vez, essa prevalência binária gera, também, o interesse das estruturas de poder em naturalizar entre os indivíduos essa lógica hierárquica, como uma ilusão para aqueles que seguem tais prescrições (Butler, 2016: 57). Além disso, pelo fato de o gênero ser construído via repetição, pelas performances e pelas estilizações do corpo inserido em uma estrutura que busca regular as relações sociais que homens e mulheres delimitam - ou mesmo em que são delimitados -, cabe ao pesquisador identificar qual noção de "mulher" é definida sob uma pretensão hegemônica e masculina.

Apontar para o caráter dicotômico e desigual das relações entre homens e mulheres, bem como problematizar o patriarcado, não significa corroborar com a existência de uma dominação universal, em que os sujeitos históricos são alheios a esse processo. Conforme salientou Raewyn Connell (2013), a masculinidade e as hierarquias a ela inerentes são, de fato, padrões hegemônicos presentes nas sociedades. A mesma afirmação é encontrada na já citada defesa, por parte de Judith Butler, da existência de uma matriz heterossexual. Em outras palavras, este padrão só é definido desde que "o consenso cultural, a centralidade discursiva, a institucionalização e a marginalização ou a deslegitimação de alternativas” estejam presentes, já que se tratam de "características amplamente documentadas de masculinidades socialmente dominantes” (Connell; Messerschimdt, 2013: 263). Portanto, ainda que a construção do gênero ambicione uma regulação dos corpos

3 Cabe ressaltar, como a própria Judith Butler $(2016: 258)$ informou, que ambas as noções aplicadas em seu trabalho foram retiradas das reflexões de Monique Wittig - principalmente a ideia de "contrato heterossexual" - e de Adrienne Rich - que, em 1980, publicou um ensaio tratando justamente do conceito de "heterossexualidade compulsória". 
e a restrição das práticas subversivas, não significa compreender essa subversão circunscrita aos mecanismos de regulação vigentes. Cabe ao pesquisador, segundo a Butler (2016: 57), avaliar "que tipo de repetição subversiva poderia questionar a própria prática reguladora da identidade?”.

\section{Possibilidades para a emancipação feminina e para a revolução feminista}

A partir da lógica construída por Firestone (1976), toda a problemática abordada anteriormente acerca da dominação masculina e dos discursos biológicos atrelados ao interesse em justificar essa dominação, configuram-se definitivamente como ações políticas. Para a autora, por mais que os homens, cada vez mais, consigam se desvencilhar das condições biológicas frente às transformações históricas, eles não estão dispostos a renunciar aos privilégios que a dominação masculina e o poder sobre as mulheres têm lhes concedido historicamente. O trabalho de Silvia Federici é um importante exemplo de como é simples visualizarmos a existência tanto dessa manutenção de privilégios como da persistência dos silenciamentos acerca das histórias das mulheres, tendo em vista que os próprios pesquisadores do materialismo histórico - interessados em tratar dos oprimidos, dos subalternizados, da exploração e da dominação do capital - ocuparam-se em manter esse contexto de exclusão. Diante dessas considerações, e seguindo a linha interpretativa de ambas as autoras, cabe questionar: como seriam realizadas, na prática, as transformações necessárias nos papéis sexuais e biológicos, uma vez que, para Firestone, a origem da dominação masculina está no processo reprodutivo e, principalmente, na maternidade e no aleitamento, considerando que somente as mulheres possuem as capacidades biológicas necessárias para esses processos?

Como alternativa revolucionária a esse contexto, a autora propõe a tomada do controle da reprodução, ou seja, do próprio corpo feminino: "para assegurar a eliminação das classes sexuais, é preciso a revolta da classe baixa (as mulheres) e a tomada do controle da reprodução: a restituição às mulheres da propriedade de seus próprios corpos, bem como do controle feminino da fertilidade humana" (Firestone, 1976: 20). Se considerada a perspectiva histórica adotada por Federici, a sugestão de Firestone ganha ainda maior substância, na medida em que a regulação dos papéis sociais referentes às mulheres foi marcada profundamente pelo interesse dos homens em limitar a importância dos corpos femininos. Como afirma Federici, ao estudar a caça às bruxas, este fenômeno constitui um exemplo fundamental da repressão aos corpos e aos comportamentos das mulheres.

Para materializar esse processo de libertação feminina de seus aspectos biológicos e reprodutivos, Firestone acredita no potencial das novas tecnologias, assim como destaca a necessidade de tomar também as instituições sociais de nutrição e de educação das crianças, para que esse papel não recaia novamente sobre 
as mulheres - e, principalmente, não as aprisione. Nesse sentido, na concepção da autora, a revolução sexual feminina, mais do que eliminar os privilégios do homem, deve almejar a eliminação da própria distinção sexual, de maneira que as diferenças genitais, biológicas e naturais não mais significariam culturalmente, tampouco teriam cargas negativas e manifestações opressivas em sociedade.

Beatriz Preciado4 (2014), em seu Manifesto Contrassexual, promoveu a atualização da discussão a respeito da necessidade de eliminação das distinções sexuais que, conforme discutido, foi levantada por Firestone. Considerado/a como um/a dos/as principais expoentes da teoria queer na atualidade, o/a filósofo/a espanhol/a Preciado apresenta, nessa obra, amplas reflexões sobre a sexualidade, os estereótipos homem/mulher, homo/hétero, natural/artificial, aprofundando conceitos e discussões contemporâneas acerca do gênero, desejo e corpo. Decretando o fim da natureza como ordem legitimadora da sujeição de determinados corpos a outros, Preciado construiu seu manifesto a partir do conceito de contrassexualidade. Para o/a autor/a, a contrassexualidade é, em primeiro lugar, "uma análise crítica da diferença de gênero e de sexo, produto do contrato social heterocentrado, cujas performatividades normativas foram inscritas nos corpos como verdades biológicas" (Preciado, 2014: 21).

A contrassexualidade estabelece a necessidade de substituição desse contrato sexual denominado Natureza, por um contrato contrassexual - nesse âmbito, os corpos não seriam reconhecidos a partir do binômio homem/mulher, mas como corpos falantes, reconhecendo-se a si mesmos dessa forma e reconhecendo os outros corpos como falantes, como possíveis de assumir todas as posições de enunciação, como sujeitos (não mais como masculinos, femininos ou perversos). De acordo com Preciado (2014), a partir desse contrato contrassexual, renunciam-se as identidades sexuais fechadas e determinadas naturalmente (baseadas na natureza), assim como os benefícios e privilégios obtidos historicamente por meio da naturalização dos efeitos sociais, econômicos e jurídicos da polarização entre homens e mulheres.

Preciado parte do mesmo argumento que sustentou as reflexões de Judith Butler em Problemas de gênero, ou seja, as reflexões sobre o gênero não pressupõem uma simples negação do sujeito, mas visam problematizar a sua naturalidade a partir da importância de compreendermos que o próprio gênero passa por um processo de naturalização5 . O próprio binarismo homem/mulher se traduz a partir de toda

4 Nesseartigo, optamos pelo duplo tratamento (feminino/masculino) de Preciado, baseados justamente na filosofia do(a) autor(a) de descrença no binômio homem/mulher, conforme trecho da entrevista publicada na sessão "Sobre o autor", do Manifesto Contrassexual: "Nasci em Burgos e vivo entre Paris e Barcelona. Sou filósofa e ensino Teoria do Gênero na Universidade de Paris VIII. Vivemos juntos minha noiva, uma cadela bulldog, um gato e eu. Não quero me reproduzir. Não creio na nação nem em Deus. Minha cadela se chama Pepa. Se sou homem ou mulher? Esta pergunta reflete uma obsessão ansiosa do ocidente. Qual? A de querer reduzir a verdade do sexo a um binômio. Eu dedico minha vida a dinamitar esse binômio. Afirmo a multiplicidade infinita do sexo!" Paul Beatriz Preciado, entrevista a Victor Amela. La Vanguardia, 1 de abril de 2008.

5 Ao mesmo tempo em que Preciado (2014) se ancora em alguns dos pressupostos anteriormente discutidos por Butler (2016), também possui importantes pontos de discordância. No capítulo "Breve genealogia do orgasmo ou o vibrador de Butler", na sua obra mais conhecida, Manifesto Contrassexual, Preciado questiona algumas "figuras" fundamentais para a análise que Butler constrói. Dentre elas, 
uma produção discursiva que busca consolidar uma determinada versão a respeito do que significa "ser homem" e "ser mulher" em dado período. Tamanha produção, continua Butler (2016), visa diretamente à construção e à naturalização de papeis sociais capazes de regular a vida social dos indivíduos. E, conforme salientou a autora, "certas configurações culturais do gênero assumem o lugar do 'real' e consolidam e incrementam sua hegemonia por meio de uma autonaturalização apta e bem sucedida" (Butler, 2016: 69). Além do mais, ressalta-se que os próprios indivíduos contribuem para a manutenção da masculinidade hegemônica, em que as funções sociais concedidas às mulheres só adquirem coerência a partir da relação hierárquica assumida para com os homens. Nas palavras da própria filósofa, "recusar-se a pressupor, isto é, a exigir a noção do sujeito desde o início, não é o mesmo que negar ou dispensar essa noção totalmente; ao contrário, é perguntar por seu processo de construção e pelo significado político e pelas consequências de tomar o sujeito como um requisito ou pressuposição da teoria" (Butler, 1998: 14).

Baseando-se em estudos de autores como Monique Wittig (que discute a heterossexualidade como regime político), Michel Foucault (que entende a noção de sexualidade como um conjunto de dispositivos sexuais modernos), dá já citada Judith Butler (que vê a identidade sexual como resultado de práticas de índole performativa) e Donna Haraway (em especial na noção de "política do ciborgue"), a proposta de Preciado (2014) parte do anseio de desnaturalizar e desmitificar compreensões tradicionais a respeito de sexo e de gênero. Nesse sentido, vai ao encontro das teorias feministas radicais de Shulamith Firestone, na medida em que a contrassexualidade constitui-se também como uma teoria do corpo situado fora das oposições binárias entre homem e mulher, masculino e feminino, heterossexualidade e homossexualidade. Assim como destacado por Firestone (1976), a revolução feminista deveria almejar a eliminação da própria distinção sexual e biológica, para que essas diferenças não mais tivessem manifestações positivas - ou negativas - para determinada parte da sociedade.

Para que tais objetivos revolucionários sejam alcançados, no capítulo conclusivo de $A$ dialética do sexo, Firestone apresenta uma série de proposições para a estruturação e construção desse sistema alternativo necessário para a efetivação da revolução feminista definitiva, tais como: a libertação das mulheres de sua biologia reprodutora, alçando mão dos meios disponíveis para tal, apostando, principalmente, nas novas possibilidades tecnológicas em termos de reprodução artificial e embriologia moderna; a redistribuição do papel de nutrição e educação das crianças entre os membros da sociedade como um todo, de maneira que essa função recaia, igualmente, entre homens e mulheres; a total autodeterminação e independência econômica, não só das mulheres como também das crianças, objetivo

Preciado discorre especialmente a respeito da figura da drag queen, que, na sua percepção, aponta limites para certas noções performativas de Butler. Enquanto Butler conclui que a heterossexualidade constitui uma paródia de gênero (baseando-se, para isso, principalmente na performance da drag queen), Preciado afirma que essa linha de análise se torna problemática ao completar o processo "de redução da identidade a um efeito do discurso, ignorando as formas de incorporação específica que caracterizam distintas inscrições performativas da identidade” (Preciado, 2014: 92). 
que deveria passar pela necessidade de mudanças fundamentais em toda a estrutura social e econômica atual; a absoluta integração das mulheres e das crianças em todos os níveis da sociedade, eliminando-se totalmente as instituições que segregam mulheres e crianças.

Essas são algumas das alternativas propostas por Firestone, que, dentre outras proposições especulativas, com relação ao futuro rumo à revolução feminista, também aborda a constituição de novas profissões, novos espaços e novas configurações familiares comunitárias (households - algo como uma estrutura comunitária substitutiva à família nuclear patriarcal). Conforme a autora destaca, essas são apenas algumas sugestões e alternativas "grosseiras", feitas por uma única pessoa e que, exatamente por isso, devem ser discutidas e aperfeiçoadas em conjunto, de maneira a melhor definirem a direção geral de uma revolução feminista. No entanto, como mote principal de suas propostas, e que deve ser essencialmente buscado para a revolução feminista definitiva, está a necessidade fundamental da produção e da reprodução da espécie humana ser simultaneamente reorganizada e reconfigurada de um modo não repressivo, igualitário e sem distinções opressivas baseadas na natureza, na biologia ou no sexo.

Judith Butler também compreende a existência de uma prática reguladora das identidades. A autora não se furtou em refletir sobre quais as possibilidades ou, melhor dizendo, quais as repetições subversivas seriam capazes de questionar essa matriz heterossexual: "o que constituiria a possibilidade de inversão, subversão ou deslocamento efetivos nos termos de uma identidade construída? Que possibilidades existem em virtude do caráter construído do sexo e do gênero?" (Butler, 2016: 58). No avançar das suas reflexões, a autora parece indicar um primeiro caminho, ao perceber que a complexidade pertencente ao campo discursivo produtor dos gêneros, indica a possibilidade de questionar toda essa estrutura, uma vez que essa multiplicidade traz consigo a diversidade de contestações e, assim, a probabilidade de ruptura com o contexto normativo (Butler, 2016: 58 ).

Além disso, quando a produção disciplinar do gênero é colocada em prática, isto é, quando é construída uma coerência aparente do gênero, ocorre o simultâneo ocultamento das descontinuidades desse gênero - os gays, as lésbicas e bissexuais, quer dizer, quando o "gênero não decorre necessariamente do sexo, e o desejo, ou a sexualidade em geral, não parece decorrer do gênero" (Butler, 2016: 194). No entanto, ainda que ocultos, isso não significa dizer que essas "descontinuidades" permanecerão invisíveis; pelo contrário, já que Butler considera a possibilidade de "desorganização e desagregação do campo dos corpos", em que é possível romper com a "ficção reguladora da coerência heterossexual". Vide como o "travestismo" busca frequentemente parodiar a própria ilusão de um gênero estável e neutro, que não assume as descontinuidades e diferenciações na relação sexo/gênero/desejo. Para a autora, essa "performance do drag brinca com a distinção entre a anatomia do performista e o gênero que está sendo performado” (Butler, 2016: 196), uma vez que 
é possível visualizar em um mesmo indivíduo as dissonâncias entre a identidade de gênero, o sexo anatômico e a performatividade do gênero ${ }^{6}$.

É viável, portanto, uma completa subversão da matriz heterossexual? Arriscamos a dizer que, nos termos das teorias levadas adiante por Butler, especificamente em seu Problemas de gênero, essa subversão ou emancipação são possíveis, desde que consideradas as próprias estruturas de poder responsáveis pela produção e repressão da categoria "mulheres". Assim, e nas palavras da própria filósofa, somente no "interior das práticas de significação repetitiva que se torna possível a subversão da identidade” (Butler, 2016: 209). Não há um corpo feminino "verdadeiro" que esteja situado fora dos termos da lei. Por isso, a subversão pensada pela autora só é viável na medida em que a própria lei se vira contra si mesma, revelando inconsistências, questionamentos e "metamorfoses inesperadas". Enfim, "o corpo culturalmente construído será então libertado, não para seu passado "natural”, nem para seus prazeres originais, mas para um futuro aberto de possibilidades culturais" (Butler, 2016: 139).

Essa subversão da matriz heterossexual compreenderia uma ruptura com as estruturas de pensamento que, ainda hoje, sustentam uma versão da história em que, raramente, as mulheres são encaradas como protagonistas? Quando passou a questionar o modo como os historiadores, até as décadas de 1970 e 1980, tratavam da presença das mulheres a partir dos processos históricos, Michelle Perrot (1984) assumiu uma crítica ferrenha acerca dos silenciamentos existentes a partir dessa relação, cuja responsabilidade, para a autora, residia na estrutura masculinista que permeava o espaço acadêmico francês. Vale lembrar, aliás, as críticas protagonizadas por Federici (2017), mencionadas ainda no início deste artigo. De todo modo, importa, segundo Perrot (1984:16), compreender que "escrever a história das mulheres é sair do silêncio em que elas estavam confinadas". Em 1998, Margareth Rago, historiadora brasileira, tratou de aprofundar as problemáticas levantadas por Perrot na década precedente, chamando a atenção para o fato de que uma teoria feminista do conhecimento ainda era incipiente no Brasil daquele período ${ }^{7}$. Ainda assim, se propôs a discutir sobre as possibilidades de construção de uma epistemologia feminista capaz de romper com o "modo dominante de produção do conhecimento científico" (Rago, 1998: 22).

6 Butler (2016, p. 197) ressalta, no entanto, que "a noção de paródia de gênero aqui defendida não presume a existência de um original que essas identidades parodísticas imitem. Aliás, a paródia que se faz é da própria ideia de um original”.

7 Em contrapartida, cabe comentar que a área da Literatura, se considerado esse mesmo período citado por Margareth Rago, já se encontrava relativamente consolidada quanto aos estudos feministas. Vide a criação, em 1985, do Grupo de Trabalho (GT) intitulado A mulher na Literatura, vinculado à ANPOLL - Associação Nacional de Pós-Graduação e Pesquisa em Letras e Linguística. No ano seguinte, com a criação da ABRALIC - Associação Brasileira de Literatura Comparada, em 1986, avançaram, conforme sublinhou Heloísa Buarque de Hollanda (1991: 8), os estudos literários interessados em colocar as mulheres como tema central. Afirmou, assim, que nos eventos realizados pela ANPOLL e pela ABRALIC, ao longo da década de 1980, foi possível notar que a "incidência de apresentações e comunicações sobre a mulher é significativa, levando-se em consideração a pouca tradição dos estudos sobre a mulher”. Para a área da História, a criação de um GT, similar ao mencionado, ocorreu somente no ano de 2001, com a oficialização do GT de Estudos de Gênero, vinculado à ANPUH, o que corrobora com a assertiva da autora quanto às fragilidades dos estudos feministas na historiografia brasileira daquele período. 
Margareth Rago, de início, tratou de ressaltar a possibilidade de existência de uma pluralidade referente a essa epistemologia, buscando destacar dois pontos que, a seu ver, são capazes de situar a teoria feminista como um novo campo de conhecimento. O primeiro consiste em situar essa teoria na "ampla crítica cultural, teórica, epistemológica em curso, ao lado da Psicanálise, da Hermenêutica, da Teoria Crítica Marxista, do Desconstrutivismo e do Pós-modernismo" (Rago, 1998: 23). Essa crítica está relacionada ao interesse dos estudos em questionar a rigidez das categorias dominantes e que se apresentam como universais, mais precisamente como categorias masculinizantes na medida em que o homem é dado como sujeitobase para as reflexões e construções teóricas. O segundo ponto, e que decorre diretamente da problematização dessas categorias, pretende a construção de novas teorias do conhecimento, reafirmando o interesse em definir um "projeto feminista de ciência alternativa, que se quer potencialmente emancipador” (Rago, 1998: 23).

A partir dessas duas colocações, a autora tratou de refletir como a consolidação desse projeto epistemológico, ou seja, "os deslocamentos teóricos produzidos pelo feminismo” (Rago, 1998: 32), influenciaram no modo como a produção historiográfica se desenvolveu a partir desse novo contexto. Citou, assim, a emergência da Nova História - ou a História Cultural - por se tratar de uma importante virada nos estudos dos historiadores acerca das mulheres, a partir do momento em que novos objetos, abordagens e teorias - incluindo a teoria feminista - foram assimilados ao saber histórico (Rago, 1998: 28). Posteriormente, a categoria gênero, que tem na historiadora Joan Scott uma de suas principais defensoras, tornou-se essencial em uma série de trabalhos historiográficos interessados em rever as categorias tradicionais e repensar o papel dos sujeitos nas relações de poder. Sendo assim, a teoria feminista tem demonstrado, no campo da História, como a emancipação ou a subversão das estruturas normativas é igualmente possível para as mulheres quando analisados os espaços de produção do conhecimento, antes excludentes e masculinos.

Ao mesmo tempo em que é essencial alcançar os espaços de construção do conhecimento científico e histórico, incluindo a categoria de gênero e a teoria feminista aos mais diversos campos de estudo e de saberes, também é fundamental, nesse processo de emancipação feminina, a apropriação de espaços de expressão artística, estética e literária. Como pontuou Beauvoir (1970: 183), "a representação do mundo, como o próprio mundo, é operação dos homens; eles o descrevem do ponto de vista que lhes é peculiar e que confundem com a verdade absoluta”. Historicamente, os homens detiveram o poder e o privilégio da escrita e da criação artística, não só construindo e perpetuando mitos e estereótipos acerca da imagem da mulher, como também silenciando e marginalizando as expressões artístico-literárias de autoria feminina ao longo dos séculos.

Nesse sentido, na concepção de Beauvoir, o envolvimento com atividades criadoras, como a literatura e as artes, configura-se como uma estratégia "para não deixar afundar no vácuo uma vida interior que não serve para nada, para se afirmar contra o dado que suporta com revolta, para criar um mundo diferente desse em que não consegue alcançar-se, ela tem necessidade de se exprimir" (Beauvoir, 1967: 473, 
grifos da autora). Nesse contexto, a escrita de autoria feminina, particularmente, assume um papel fundamental para esse processo de libertação feminina, na medida em que se constitui como um espaço para sua expressão singular, para a construção de si como sujeito, para a manifestação de injustiças e opressões, para a reivindicação de condições mais igualitárias e para a representação do mundo (que sempre foi privilégio dos homens) a partir de uma perspectiva diferente: as concepções, visões, histórias e experiências de mulheres.

\section{Considerações finais}

Este trabalho permitiu refletirmos sobre a importância de os pesquisadores compreenderem as relações sociais a partir do modo como são constituídas as dinâmicas de poder entre homens e mulheres diante dos mais distintos contextos históricos. A preocupação em mapear essas relações foi localizada temporalmente a partir da emergência dos movimentos feministas que marcaram o Ocidente a partir da segunda metade do século XX - embora seja possível identificar algumas reflexões mais pontuais antes mesmo desse período. Desde a publicação de O Segundo Sexo, da filósofa francesa Simone de Beauvoir, pode-se afirmar que as sociedades presenciaram uma verdadeira e organizada tomada de consciência por parte das mulheres, fossem elas pertencentes aos meios acadêmicos ou entre as interessadas em lutar publicamente por direitos políticos, acerca da dominação masculina e da sua dimensão histórica. Essa consciência referente à existência dessa dominação, considerada não apenas sob um caráter histórico, mas, também, enraizada por parte dos homens, foi o primeiro passo definido por diversas feministas interessadas em situar as relações entre homens e mulheres, a partir do campo do poder. Também serviu para que afirmassem que este campo é utilizado como espaço capaz de silenciar e excluir as mulheres da vida pública.

A partir dessa constatação, uma série de teóricas feministas se dispôs não somente a refletir sobre o caráter dessa dominação, mas, principalmente, a problematizá-la por meio da construção de verdadeiras teorias cujo objetivo primordial residia em apontar os meios pelos quais as mulheres subverteriam essa lógica dominante. Shulamith Firestone foi uma das expoentes desse contexto, optando por um posicionamento mais radical ao definir a necessidade de as mulheres empreenderem uma verdadeira "revolução feminista", capaz de libertá-las do controle vigente sobre seus corpos e do sexismo que, no seu entendimento, marcava decisivamente as relações entre homens e mulheres.

Entretanto, essa emancipação, ou revolução feminista, não se dará apenas sobre um único campo de estruturação e atuação da dominação masculina, cuja inserção é presente nas mais distintas sociedades. A subversão das estruturas dominantes implica na existência de práticas de emancipação que considerem os mais distintos universos das relações entre homens e mulheres, uma vez que, conforme analisado 
ao longo deste trabalho, os silenciamentos percorreram desde a regulação dos corpos femininos ao modo como foram interpretadas - ou negligenciadas? - as suas histórias. Sendo possível concluir que as estruturas de poder - ou a matriz heterossexual, segundo Butler (2016) - não assumiram uma única forma de atuação diante do interesse em normatizar os corpos e comportamentos das mulheres, é viável afirmar que esse processo revolucionário demandará uma diversidade de posicionamentos e práticas sociais capazes de questionar a vigência dessas estruturas.

As diversas obras analisadas ao longo deste trabalho possibilitaram a compreensão de que esse processo subversivo e, a nosso ver, revolucionário, não possui um único modelo a ser seguido, muito por conta das distintas posições defendidas pelas teóricas feministas a respeito dessa emancipação e, até mesmo, de como devemos reconhecer e problematizar a existência da dominação masculina. Ainda assim, acredita-se que as discussões empreendidas ao longo dessas páginas servem de parâmetro para a reafirmação do que foi defendido acima, ou seja, de que a revolução feminista só será possível caso prevaleça o entendimento de que a sua efetividade possui uma relação de dependência com a existência de múltiplas frentes de subversão.

\section{Referências bibliográficas}

BEAUVOIR, Simone de. O segundo sexo: a experiência vivida. 2. ed. Trad. Sérgio Milliet. São Paulo: Difusão Europeia do Livro, 1967.

BEAUVOIR, Simone. O segundo sexo: fatos e mitos. Tradução de Sérgio Milliet. 4. ed. São Paulo: Difusão Europeia do Livro, 1970.

BUTLER, Judith. "Fundamentos contingentes: o feminismo e a questão do 'pósmodernismo"'. Cadernos Pagu, Campinas, n. 11, v. 1: p. 11-42, 1998.

BUTLER, Judith. Problemas de gênero. Tradução de Renato Aguiar. Rio de Janeiro: Editora Civilização Brasileira, 2016.

BUTLER, Judith. Notes towards a performative theory of assembly. Harvard: Harvard University Press, 2015.

CONNEL, Robert W; MESSERSCHIMDT, James W. "Masculinidade hegemônica: repensando o conceito”. Estudos Feministas, Florianópolis, n. 21: p. 241-282, jan./abr. 2013.

DE LAURETIS, Teresa. Technologies of Gender: Essays on Theory, Film, and Fiction. Bloomington: Indiana University Press, 1987.

FEDERICI, Silvia. Calibã e a Bruxa: mulheres, corpo e acumulação primitiva. Trad. de Coletivo Sycorax. São Paulo: Elefante, 2017. 
FIRESTONE, Shulamith. A dialética do sexo. Trad. Vera Regina Rabelo Terra. Rio de Janeiro: Editorial Labor do Brasil, 1976.

FOUCAULT, Michel. História da sexualidade I: a vontade de saber. Tradução de Maria Thereza da Costa Albuquerque e J. A. Guilhon Albuquerque. Rio de Janeiro: Graal, 1988.

HARAWAY, Donna. Ciencia, cyborgs y mujeres: la reinvención de la naturaleza. Traducción de Manuel Talens. Madrid: Ediciones Cátedra, 1995.

HOLLANDA, Heloísa Buarque de. "Estudos sobre a mulher e literatura no Brasil: uma primeira abordagem”. Papéis Avulsos, v. 1: p. 1-30, 1991.

MUZART, Zahidé Lupinacci (Org.). Escritoras brasileiras do século XIX. Vol. I. Florianópolis: Editora Mulheres, 1999.

MUZART, Zahidé Lupinacci (Org.). Escritoras brasileiras do século XIX. Vol II. Florianópolis; Santa Cruz do Sul: Editora Mulheres; Edunisc, 2004.

MUZART, Zahidé Lupinacci (Org.). Escritoras brasileiras do século XIX. Vol. III. Florianópolis: Editora Mulheres, 2009.

PERROT, Michelle. Une Histoire des Femmes est-elle possible? Paris: Rivage, 1984.

PRECIADO, Beatriz. Manifesto Contrassexual: práticas subversivas de identidade sexual. Tradução de Maria Paula Gurgel Ribeiro. São Paulo: n-1 edições, 2014.

RAGO, Margareth. "Epistemologia Feminista”. In: PEDRO, Joana Maria; GROSSI, Miriam Pilar (Orgs). Masculino, Feminino, Plural: Gênero na interdisciplinaridade. Florianópolis: Editora das Mulheres, 1998.

RANKE-HEINEMANN, Uta. Eunucos pelo reino de Deus: mulheres, sexualidade e a Igreja Católica. Trad. de Paulo Fróes. Rio de Janeiro: Record; Rosa dos Tempos, 1996.

SCHMIDT, Rita Terezinha. “Quem reivindica a identidade?”. Desenredo. Revista do Programa de Pós-Graduação em Letras da Universidade de Passo Fundo, n. 1, v. 4: p. 49-6o, jan./jun. 2008. Disponível em: <http://www.upf.br/seer/index.php/rd/article/ view/546/350>. Acesso em: 15 maio. 2019.

WITTIG, Monique. The Straight Mind and other essays. Boston: Beacon Press, 1992.

Recebido em 13/o6/2019.

Aceito em 10/04/2020. 